International Journal of Multidisciplinary Research AND ANALysis

ISSN[Online] : 2643-9875 || ISSN[Print] : 2643-9840

Volume 3 Issue 09 September 2020

DOI: 10.47191/ijmra/v3-i9-06, Impact Factor : 5.522

Page No : $102-107$

\title{
Theoretical Study of the Parameters of the Discrete Drum Set Teeth on Fiber Movement
}

\author{
${ }^{1}$ K.I. Ahmedov, ${ }^{2}$ A.Q. Nematov \\ ${ }^{1}$ Senior teacher, Tashkent Institute of Textile and Light Industry, \\ ${ }^{2}$ Assistant Lecturer, Tashkent Institute of Textile and Light Industry,
}

\section{ABSTRACT}

In the article, we will consider a dynamic analysis of the design and parameters of the recommended spinning machine, which provides a uniform supply of fibers to the spinning chamber to obtain high-quality filament in the working chamber of the damaging drum. An accurate calculation of the parameters is required while ensuring the parallel movement of the flows. During the period of time the volume changes in the working chamber of the damaging drum of the recommended pneumatic spinning machine. It is known that the rotational speed of the drum is very high. During this period, a tape of fibers receives a lot of blows from the sharp top of the tooth saw the drum. To reduce the impact force, designers recommend convex saws. We know from the theory of operation of spinning chambers, during the discrediting of fibers, in the surface of the spinning chambers, the fiber flow should be mutually parallel, the most basic fiber flow with each other should be at a great distance. Only, the achievement of these qualities depends on the physico-mechanical properties and length of the fibers. During the discredit, the saw of the drum combs the bands. In this process, what part of the fiber hits the saw of the drum, this deteriorates and the process of discrediting. As a result, the quality of the resulting yarn is deteriorating. Here aerodynamic laws give the expected result, therefore, it is necessary to undergo a dynamic analysis of the design and parameters of the recommended spinning machine, which ensures a uniform supply of fibers into the spinning chamber.

\section{KEYWORDS}

Fiber, working chamber, defamatory drum, volume, tooth, yarn, aerodynamics.

\section{INTRODUCTION}

The existing design of discreting drum leads to the breakage of the threads of pneumo mechanical spinning machines in the process of combing, non-parallel combing of the coils, the formation of coils in the process of sampling. This has a significant negative impact on the quality of the yarn. The improved construction of the discrete drum of pneumomechanical spinning machines helps to eliminate the existing shortcoming in the combing process. (Fig. 1) In turn, ensuring that the flow of fibers in the working chamber of the discrete drum of the pneumomechanical spinning machines moves in parallel with each other depends on the parameters of the discrete drum and geometric shape of the headset saw tooth. This prevents from getting quality yarn and breaking a lot of yarn.
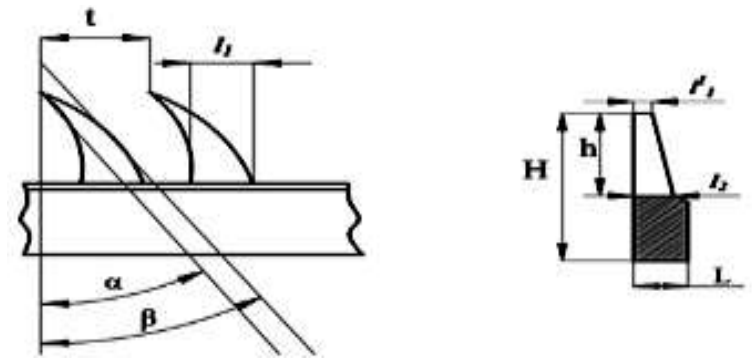

Figure 1. Construction of VD - 330 Discretion Drum

In order to obtain quality yarn and prevent multiple yarn breakage, it is necessary to calculate the parameters in precise values while ensuring the parallelism of the fiber flow in the volume change range in the working chamber of the discrete drum of the pneumatic spinning machine. To do this, use the parameters of the discrete drum set recommended below. 


\section{THEORETICAL RESEARCH}

$1 M M^{2}$ - formula for determining the volume of fibers flowing on the surface.

$$
V_{0}=0.1 \cdot h \cdot\left(1-\frac{l_{1} \cdot l_{2}}{3 \cdot L \cdot t}\right) \cdot S_{0}
$$

Here is the surface $S_{0}=1 \mathcal{M M}^{2} h_{-}$tooth height, ${ }^{t-}$ tooth step, $l_{2}-$ the thickness of the tooth base, L- thickness of teeth, $l_{1}-$ width of tooth base, $\quad l_{1}^{\prime}-$ thickness of tooth surface.

We analyze the overall surface area in our theoretical research.

$$
S=t \cdot h=2.5 \cdot 1.8=4.5 M^{2}
$$

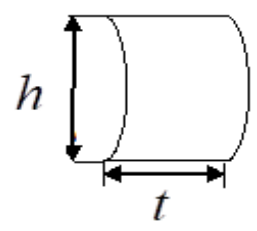

Two surface spaces of the headset were obtained from this surface, and the motion of the fibers flowing through this surface was theoretically analyzed. Analysis of the movement of fibers along the total surface between the given tooth steps in terms of volume change.

$$
V=0.1 \cdot h \cdot\left(1-\frac{l_{1} \cdot l_{2}}{3 \cdot L \cdot t}\right) \cdot S
$$

The change in fiber size from $h 1$ to $h 2$ in the range for tooth height

$$
d V=\int_{h_{1}}^{h_{2}} 45 \cdot h \cdot\left(1-\frac{l_{1} \cdot l_{2}}{3 \cdot L \cdot t}\right) d h \Rightarrow \Delta V=22.5 \cdot\left(1-\frac{l_{1} \cdot l_{2}}{3 \cdot L \cdot t}\right) \cdot\left(h_{2}^{2}-h_{1}^{2}\right)
$$

The change in the size of the fibers from $t 1$ to $t 2$ for the tooth step

$$
d V=\int_{t_{1}}^{t_{2}} 45 \cdot h \cdot\left(1-\frac{l_{1} \cdot l_{2}}{3 \cdot L \cdot t}\right) d t \Rightarrow \Delta V=\frac{h}{10} \cdot\left[\left(t_{2}-\frac{l_{1} \cdot l_{2}}{3 \cdot L} \ln \left|t_{2}\right|\right)-\left(t_{1}-\frac{l_{1} \cdot l_{2}}{3 \cdot L} \ln \left|t_{1}\right|\right)\right]
$$

The size change of the fibers from $L 1$ to $L 2$ for the tooth thickness

$$
d V=\int_{L_{1}}^{L_{2}} 0.1 \cdot h \cdot\left(1-\frac{l_{1} \cdot l_{2}}{3 \cdot L \cdot t}\right) d L \Rightarrow \Delta V=45 \cdot h \cdot\left[\left(L_{2}-\frac{l_{1} \cdot l_{2}}{3 \cdot t} \ln \left|L_{2}\right|\right)-\left(L_{1}-\frac{l_{1} \cdot l_{2}}{3 \cdot t} \ln \left|L_{1}\right|\right)\right]
$$

The change in the size of the fibers from $/ 1.1$ to $/ 1.2$ for the width of the tooth base

$$
d V=\int_{l_{1.1}}^{l_{1.2}} 45 \cdot h \cdot\left(1-\frac{l_{1} \cdot l_{2}}{3 \cdot L \cdot t}\right) d l_{1} \Rightarrow \Delta V=22.5 \cdot h \cdot\left(\Delta l_{1}-\frac{l_{2}}{3 \cdot L \cdot t}\right) \cdot\left(l_{1.2}^{2}-l_{1.1}^{2}\right)
$$

The change in the size of the fibers from $/ 2.1$ to / 2.2 for the thickness of the tooth base

$$
d V=\int_{l_{2.1}}^{l_{22}} 45 \cdot h \cdot\left(1-\frac{l_{1} \cdot l_{2}}{3 \cdot L \cdot t}\right) d l_{2} \Rightarrow \Delta V=22.5 \cdot h \cdot\left(\Delta l_{2}-\frac{l_{1}}{3 \cdot L \cdot t}\right) \cdot\left(l_{2.2}^{2}-l_{2.1}^{2}\right)
$$

\section{OUTCOME ANALYSIS}

In the working chamber of the discreting drum of a pneumatic spinning machine, it is necessary to calculate the parameters in exact values to ensure the parallelism of the fiber flow in the range of volume changes. Graphs of tooth height, pitch, width, and thickness of the base depending on the size of the fibers on the surface. 


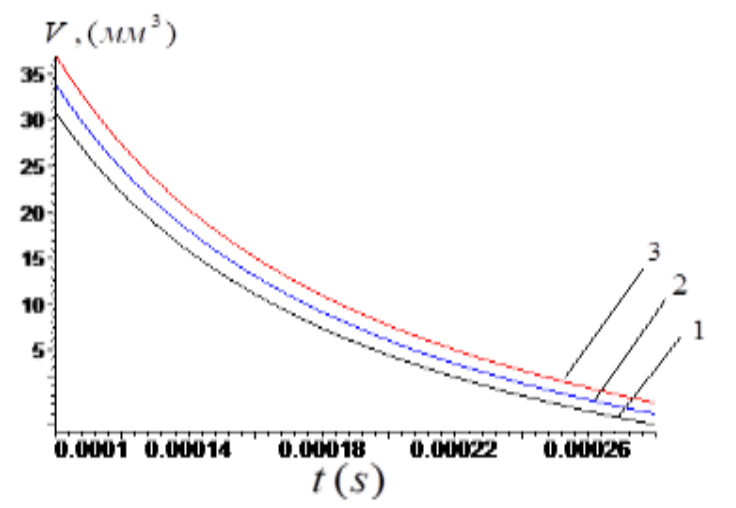

a-picture. The graphs of the working height $S_{0}=1 \mathcal{M M}^{2}$ depending on the volume of the fiber flow in the time interval $t=2.8 \cdot 10^{-4} c$ on the surface : at different values of heights $h_{1}=1,8 \mathrm{MM}, h_{2}=1,85 \mathrm{MM}, h_{3}=1,9 \mathrm{MM}$

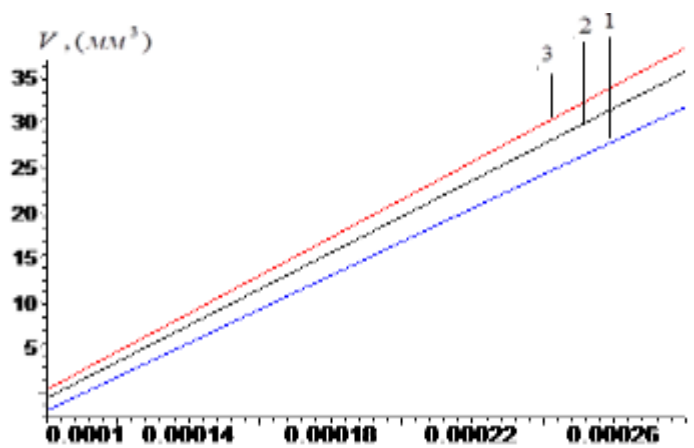

$t(s)$
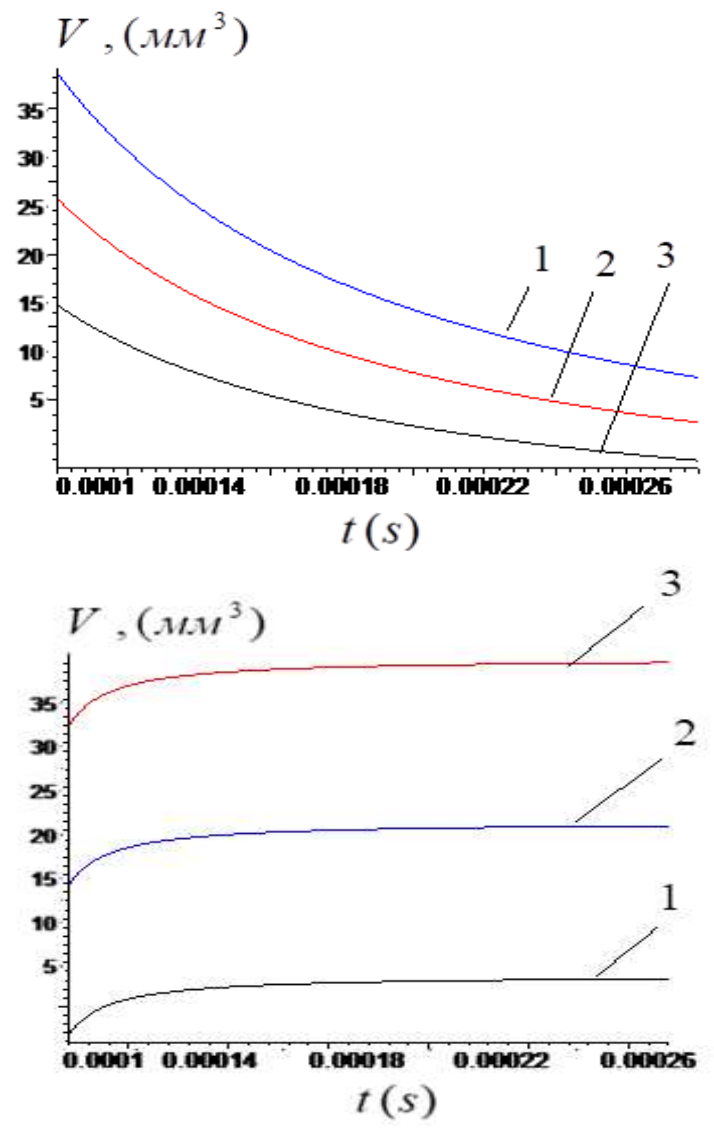

b-picture. Volume-dependent graphs of viber flow on the $S_{0}=1 \mathcal{M M}^{2}$ surface $t=2.8 \cdot 10^{-4} c$ of the tooth steps: at different values of the tooth steps

$$
t_{1}=2,5 \mathrm{MM}, t_{2}=2,6 \mathrm{MM}, t_{3}=2,7 \mathrm{MM}
$$

c- picture. Graphs of the width of the tooth base on the surface of $S_{0}=1 \mathcal{M M}^{2}$ surface in the time interval $t=2.8 \cdot 10^{-4} c$ fibers depending on the volume : the width of the tooth base at different values in

$$
l_{11}=0.02 \mathrm{MM}, l_{12}=0.03 \mathrm{MM} l_{13}=0.04 \mathrm{MM}
$$

d-picture. Graphs of the thickness of the tooth base on the $S_{0}=1 \mathcal{M M}^{2}$ surface $t=2.8 \cdot 10^{-4} c$ in the time interval depending on the volume of the fiber flow: the thickness of the tooth base at different values

$$
l_{21}=0.9 \mathrm{MM}, l_{22}=0.93 \mathrm{MM} l_{23}=0.96 \mathrm{MM}
$$

$1 M M^{2}$ - the formula for combing the flow of fibers on the surface at the expense of the angle of inclination of the tooth

$$
K=\cos ^{2} \alpha \cdot e^{\left[\frac{\mu \cdot l}{\pi}\left(\frac{1}{L}+\frac{1}{t}\right)\right]}
$$

$\mu-$ the coefficient of friction between the fiber and the table

$L-$ tooth thickness, $t-$ tooth pitch, $l-$ fiber length

$\alpha-$ the angle of inclination of the discrete drum teeth 


$$
K=(\cos (\alpha))^{2} \cdot e^{\left(\mu \cdot \frac{\frac{t+L}{t \cdot L}}{\pi}\right)}
$$

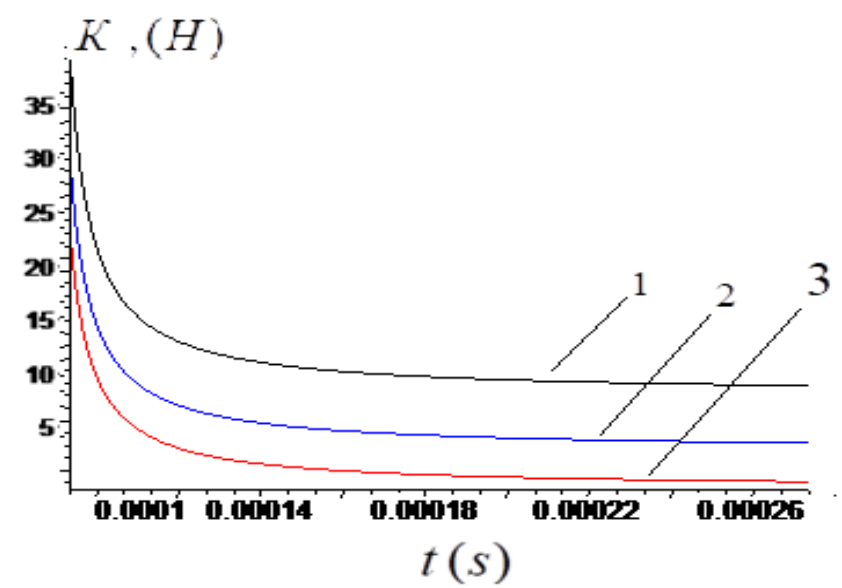

Graph of the coupling force depending on the angle of inclination of the tooth : the angles of deflection at different values $\alpha_{1}=54^{0}, \alpha_{2}=58^{0}, \alpha_{3}=62^{0}$

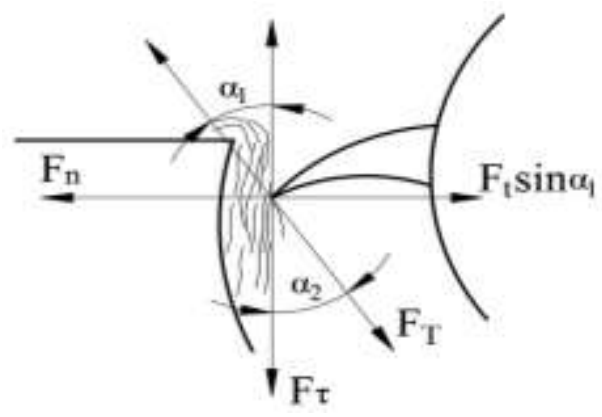

Figure 4. Performance analysis of the discretion drum.

$F_{\tau}-$ we divide the tensile strength of the teeth into two components

$F_{N}-$ normal force, $F_{T}-$ tangential force, angles are considered to be mutually equal, that is $\alpha_{1}=\alpha_{2}$.

The motion of the fiber is determined using the force momentum formula for the time interval $\Delta \tau-$ for a fiber of mass $m_{t}-$ in the $\Delta V$ - volume range.

$$
F_{\tau} \Delta \tau=m_{t}\left(\vartheta_{2}-\vartheta_{1}\right)
$$

$\vartheta_{1}$ - the speed of the discreting drum

$\vartheta_{2}$ - the combined speed of the discrete drum with the fiber

The motion of the total fibers in the $\Delta X$ interval $\Delta \tau$ - time interval.

$$
\Delta X=\Delta \tau \cdot \vartheta_{\check{y} p}
$$

We determine the total mass of fibers in the $\Delta V$ volume range

$$
m_{y M}=m_{t} \cdot n
$$

here: $m_{t}-$ is the mass of a single fiber, $n-$ is the number of fibers.

$$
\text { Average speed } \quad \vartheta_{\check{y} p}=\frac{\vartheta_{1}+\vartheta_{2}}{2}
$$

WE determine the tooth $V$ - volume between the phases of the headset by the fiber capacity. Taking into account the effect of the discretion drum on the surface of the tooth $S$ - , and using the volumetric destiny $\delta$ - of the fiber, we derive the expression and the mass of the fibers is equal to $m=V \cdot S \cdot \delta$ 
From here we determine the change in the surface area of the fibers of the $1 M M^{2}$ surface.

$$
m_{t}=0.1 \cdot h \cdot S \cdot\left(1-\frac{l_{1} \cdot l_{2}}{3 \cdot L}\right) \cdot \delta
$$

We take the value of equation (4) to equation (5)

$$
\begin{gathered}
F_{\tau} \Delta \tau=0.1 \cdot h \cdot S \cdot \delta \cdot\left(1-\frac{l_{1} \cdot l_{2}}{3 \cdot L}\right) \cdot\left(\vartheta_{2}-\vartheta_{1}\right) \\
\Delta \tau=\frac{\Delta X}{\vartheta_{\check{y} p}}=\frac{2 \cdot \Delta X}{\vartheta_{1}+\vartheta_{2}}
\end{gathered}
$$

We put the value of equation (6) in equation (5) and from the following equation.

$$
F_{\tau}=\frac{0.1 \cdot h \cdot S \cdot \delta \cdot\left(1-\frac{l_{1} \cdot l_{2}}{3 \cdot L}\right) \cdot\left(\vartheta_{2}^{2}-\vartheta_{1}^{2}\right)}{2 \cdot \Delta X}
$$

The resulting equation $1 M M^{2}$ is a formula that depends on the parameters of the sampling drum using an experimental force to ensure the parallel movement of the flow of fiber on the surface. $h-$ tooth height, $t-$ tooth pitch, $l_{2}-$ tooth base thickness, $L-$ tooth thickness, $l_{1}-$ tooth base width.

graphs of the linear velocity of the discrete drum of the binding force of the total fibers on the surface $-1 M M^{2}$ : $v_{1,1}=352 \mathrm{M} / \mathrm{c}, v_{1,2}=379 \mathrm{M} / \mathrm{c}, v_{1,3}=406 \mathrm{M} / \mathrm{c}$ linear velocities at different values.

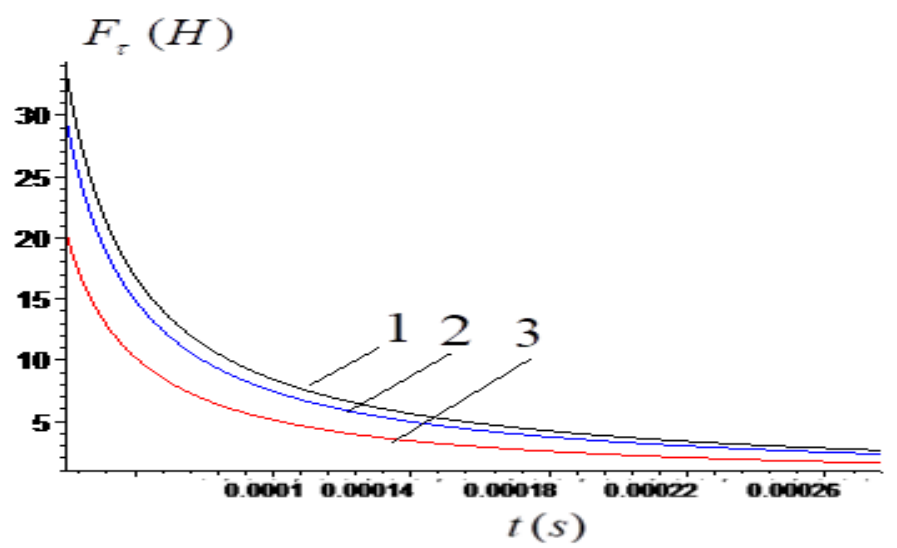

\section{CONCLUSION}

Theoretical analysis of the flow of fibers in the working chamber of the discretion drum between the teeth was calculated using the exact values of the parameters of the tooth that affect the movement of the fiber, and graphs were given.

\section{REFERENCES:}

1) Morikawa T., Horiuchi T. Quality of yarns produced by Open-end BD-440 Spinninng Machines and of final produkts // Journal of the Textile Machinery of Japan, 2014. Vol.20. P.58-66.

2) Marc Arsenault. Mechanism and Machine Theory // Mechanism and Machine Theory, volume 129 (2018) 175-190 p.

3) Y.V. Pavlov i dr. Teoriya protsessov, texnologiya i oborudovaniye pryadeniya xlopka i ximicheskix volokon. Ivanovo, IGGL 2016. Uchebnik, $392 \mathrm{~s}$.

4) Bezveretennoye pryadeniye, pod. Red. Y.V. Pavlov, «Legkaya i pishevaya promishlennost», 2017. $294 \mathrm{~s}$.

5) G.I.Magauzov. K.V.Sergeyev. Ustroystvo i obslujivaniye pnevmomexanicheskix pryadilnix mashin. Izdatelstva «Legprombitizdat» 1985.

6) Pitayushiy silindr pryadilnogo ustroystva, polezniy model Uzbekistan, FAP 00688.

7) A.Dj.Djurayev, K.J.Jumaniyazov, S.L.Matismailov, O.A.Mirzayev, A.Dovgan. Pitayushiy silindr pryadilnogo ustroystva. Patent № FAP 00688, Byul. № 1, 31.01.12g. 
8) Myachenkov V.I., Malsev V.P. «Metodi i algoritmi raschyota prosranstivennix konstruksiy na EVM YES». M.Mashinostroyeniya, 1984.-280st.

9) A.S. Volmir «Nelineynaya dinamika plastinok i obolochok»

10) Mavlanov T. «Dinamika vyazkouprugix osesimmetricheskix prizmaticheskix konstiruksii»

11) V.P.Sherbakov Prikladnaya i strukturnaya mexanika voloknistix materialov. -M. TISO PRINT, 2013.,s. 304.

12) Patent UZ № FAP 00845. Igolchatiy barabanchik pnevmomexanicheskoy pryadilnoy mashini Djurayev A.Dj., Jumaniyazov K., Matismoiloa S., Mirzayev O., Dovgan A. // Rasmiy axborotnoma. -2017. -№ 10.

13) Matthews, Ronald C.; Weaver, Wayne W.; Robinett, Rush D., «International Journal Of Electrical Power \& Energy Systems». Tom: 98 str. 315-322 Opublikovano: Jun 2018.

14) Zeydal A.N. Matematicheskaya obrabotka rezultatov eksperimentov. -M.: «Nauka», 1998 g. S.95.

15) Kirschner E-Zur. Gleichmassigkeit von Offen-End-Garden - Einfluss des Bandeinzuges // Journal of Germany «Melliand Textileberichte», 2011. №3. R.21-26.

16) Y.V. Pavlov i dr. Teoriya protsessov, texnologiya i oborudovaniye pryadeniya xlopka i ximicheskix volokon. Ivanovo, IGGL 2011. Uchebnik, $392 \mathrm{~s}$

17) Shin I.G., Shodmonkulov Z.A., Axmedov K.I., Nurullaeva X.T., Islamova G.X., Muminov M.R. Texnik mexanika: darslik - T., 2018. 211-215 S.

18) Pavlov Y.M. i dr. Teoriya protsessov texnologii i oborudovaniya pryadeniya xlopka i drugix ximicheskix volokon: Uchebnik. Ivanovo: IGTA, 2000. S.392.

19) Myachenko V.I. Teoreticheskoye issledovaniye protsessa diskretizatsii voloknistix materialov // "Injenerniy jurnal MTT», 2014. №6. S.143. 